\title{
Total Collision Cross Sections for the Interaction of Atomic Beams of Alkali Metals with Gases*†
}

\author{
Erhard W. Rothe $\ddagger$ and Richard B. Bernstein \\ Chemistry Department, University of Michigan, Ann Arbor, Michigan
}

(Received June 18, 1959)

\begin{abstract}
Total collision cross sections $(Q)$ for the interaction of atomic beams of $\mathrm{K}$ and $\mathrm{Cs}$ with a number of molecules were measured with an apparatus of $30^{\prime \prime}$ angular resolution. Although absolute determinations of $Q$ are difficult, relative values are readily obtained $( \pm 3 \%)$. Results are reported as the ratio $\left(Q^{*}\right)$ of the cross section for a given molecule to that of argon for the same beam atom. Seventy-seven molecules (of varied complexity and reactivity) were studied with $\mathrm{K}$ and 16 with $\mathrm{Cs}$ beams. $Q^{*}$ ranged from 0.29 to 2.8 .

The data were correlated using the Massey-Mohr theory, assuming an attractive intermolecular potential $V(r)=-C / r^{6}$. For this case $Q=b\left(C / v_{r}\right)^{2 / 5}$, where $v_{r}$ is the relative velocity and $b$ a known constant. $C$ was estimated from standard formulas for the London dispersion and dipole-induced dipole forces, using known refraction and dipole moment data. The theoretical values of $Q$ differ by a nearly constant factor from the experimental results; thus values of $Q^{*}$ are predicted with good accuracy. The deviation between $Q_{\text {cale }}{ }^{*}$ and $Q_{\text {obs }}{ }^{*}$ was $< \pm 3 \%$ for $57 \%$ (and $< \pm 10 \%$ for $87 \%$ ) of the molecules. Most of the large deviations occurred for the light gases.
\end{abstract}

\section{INTRODUCTION}

C ONSIDERABLE information about intermolecular forces may be obtained from studies of the scattering of a beam of molecules by a gas. The molecular beam method allows for the detection of very small angle deflections; thus the total collision cross section is a measure of the "maximum interaction sphere" of the two molecules.

The results of earlier investigations ${ }^{1-6}$ have suggested the need for quantum theory in any proper description of the experimental phenomena. Massey and $\mathrm{Mohr}^{7}$ have obtained an expression which relates total elastic collision cross sections with the intermolecular attractive potential.

Most previous molecular beam cross-section measurements have been confined to a few scattering gases (mainly inert gases and homonuclear diatomic molecules). For these cases, the attractive intermolecular interaction is identified with the London dispersion force only. There appears to be little information in the literature on the general applicability of the theory to scattering by molecules. A number of additional features must be considered in connection with molecular scattering, including:

(1) dipole-induced dipole (and dipole-dipole) forces if one (or both) of the molecules possess a dipole moment,

\footnotetext{
* Paper presented at 135th National Meeting of the American Chemical Society, Boston, Massachusetts, April 1959.

$\dagger$ For further details, see Ph.D. dissertation, E. W. Rothe, University of Michigan (1959), available from University Microfilms, Ann Arbor, Michigan.

† Present address( Physics Section, Convair-San Diego, Division of General Dynamics Corporation, San Diego, California.

${ }_{1}$ W. Mais, Phys. Rev. 45, 773 (1934).

${ }^{2}$ S. Rosin and I. Rabi, Phys. Rev, 48, 373 (1935).

${ }^{3}$ P. Rosenberg, Phys. Rev. 55, 1267 (1939).

¿I. Rabi, Rev. Sci. Instr. 6, 251 (1935)

5 Jawtusch, Schuster, and Jaeckel, Z. Physik 141, 146 (1955).

$6 \mathrm{~K}$. Kodera and T. Tamura, Bull. Chem. Soc. Japan 31, 206 (1958).

${ }^{7}$ H. S. W. Massey and C. B. O. Mohr, Proc. Roy. Soc. (London) A144, 188 (1934).
}

(2) possible anisotropy of the intermolecular potential,

(3) inelastic scattering involving, e.g., vibrational transitions, chemical reaction, ${ }^{8}$ etc.

It was thought to be of interest to examine a large number of molecules, both simple and complex, chemically inert as well as reactive, to investigate the general applicability of the theory and the possible importance of inelastic scattering. The effect of the direct-dipoledipole and the dipole-induced dipole molecular interactions as well as the dispersion forces ought to be observable.

In the present paper, results are presented for the scattering of beams of $\mathrm{K}$ and Cs by a variety of scattering molecules. The total collision cross sections were obtained and compared with values predicted theoretically for elastic scattering. A forthcoming paper will report results for $\mathrm{CsCl}$ beams, with particular emphasis on the direct dipole-dipole forces.

\section{APPARATUS $\dagger$}

The schematic arrangement of the main components of the apparatus is presented in Fig. 1. Not shown is the vacuum envelope ( 8 in. diam., 24 in. long), which is divided by a bulkhead at $\mathrm{C}$ into separately pumped regions (the "oven chamber" and the "detector chamber"). Typical operating pressures were $5 \times 10^{-7}$ and $1 \times 10^{-7} \mathrm{~mm} \mathrm{Hg}$ in the respective chambers. Large liquid nitrogen traps and baffles were located in each chamber.

The oven A (of Monel) was similar to that of Miller and Kusch, ${ }^{9}$ employing their "ideal slit," whose width was $0.0025 \pm 0.001 \mathrm{~cm}$. The oven temperature was measured with a Chromel-Alumel thermocouple in a suitable well.

The scattering chamber was somewhat similar to

${ }^{8}$ E. H. Taylor and S. Datz, J. Chem. Phys. 23, 1711 (1955).

${ }^{9}$ R. Miller and P. Kusch, Phys. Rev. 99, 1314 (1955). 


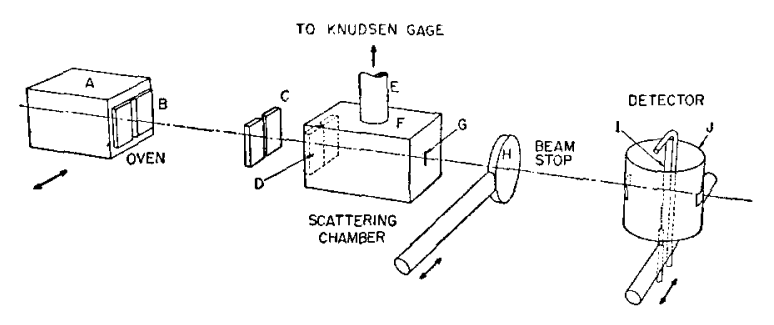

FIG. 1. Schematic view of the molecular beam scattering apparatus.

that of Estermann et al. ${ }^{10}$ Its collimating slit (D) was similar to the oven slit (B); its width was identical. The inlet and exit channels were each $1.27 \mathrm{~cm}$ long, $0.38 \mathrm{~cm}$ high and $0.028 \mathrm{~cm}$ wide; the central cavity was $2.53 \mathrm{~cm}$ in length. The effective scattering path $d$ was taken to be: $1.27+2.53+1.27 / 2=4.44 \mathrm{~cm}$.

A conventional Langmuir-Taylor surface ionization detector was used. The tungsten ${ }^{11}$ filament (I) was $0.0025 \pm 0.0005 \mathrm{~cm}$ in diameter and $c a 5 \mathrm{~cm}$ long. It was heated to about $1500^{\circ} \mathrm{K}$ by $75 \mathrm{ma}$ dc and was biased by $+90 \mathrm{v}$ relative to the ion collector $(\mathrm{J})$. A preamplifier containing a Victoreen 5800 electrometer tube with a $2 \times 10^{10}$-ohm grid resistor was followed by a standard inverse feedback dc amplifier and a $10-\mathrm{mv}$ strip chart recorder. Typical ion currents were in the range of $10^{-10} \mathrm{amp}$, corresponding to a beam intensity of $6 \times 10^{8}$ atoms $/ \mathrm{sec}$.

The distance from the slit (B) to slit (D) was 11.12 $\mathrm{cm}$; from the latter to the detector (I) was $19.68 \mathrm{~cm}$. The calculated half-width of the unscattered beam at the detector is thus $0.007 \mathrm{~cm}$; the observed value was about twice this value. The angle subtended at the midpoint of the scattering path by the detector wire is about $30^{\prime \prime}$, taken as the nominal resolution of the apparatus.

The scattering gas inlet manifold included a highvacuum pumping system, a needle valve for controlled leak of the gas from a reservoir into the scattering chamber, and a Knudsen gauge. The gauge and chamber were placed so that the pressure drop in the tubing between them was due only to the very small flow effusing from the scattering chamber, and was therefore negligible. The Knudsen gauge ${ }^{12}$ was of the Klumb and Schwartz ${ }^{13}$ design. Its calibration was linear (by comparison with an ionization gauge) and virtually independent of the gas composition; its sensitivity was $6.6 \times 10^{-6} \mathrm{~mm} \mathrm{Hg} / \mathrm{mm}$ scale deflection (by calibration with a McLeod gauge). The working range of pressure

\footnotetext{
${ }^{10}$ Estermann, Foner, and Stern, Phys. Rev. 71, 250 (1947).

${ }^{11}$ For some poly-halogen scattering gases (e.g. $\mathrm{CCl}_{4}$ ) it was necessary to oxidize the filament (poisoning of the original oxygen-free surface gradually lowered the ionization efficiency).

12 The gauge was constructed and kindly provided by Dr. G. A. Miller.

${ }^{13}$ H. Klumb and H. Schwarz, Z. Physik 22, 418 (1944).
}

in the scattering chamber ${ }^{14}$ was from $1 \times 10^{-6}$ to $2 \times 10^{-4}$ $\mathrm{mm} \mathrm{Hg}$; although the absolute value of the pressure was uncertain by $\pm 10 \%$, relative values were known to $\pm 2 \%$.

\section{EXPERIMENTAL PROCEDURE}

Optical alignment of the components of the beam apparatus with a telescope preceded final alignment with the beam. The oven contents were degassed about 2 days at $c a .125^{\circ} \mathrm{C}$. After a period of 20 to $30 \mathrm{~min}$ at the desired operating point the oven temperature and beam intensity had stabilized and measurements were begun.

The beam intensity was measured for 10 to 20 values of scattering gas pressures corresponding to 5-95\% attenuation of the beam. The beam was interrupted frequently to check the zero line; the $100 \%$ transmittance line was recorded before and after each series of points during evacuation of the scattering chamber. Plots of $\log \left(I / I_{0}\right)$ vs $P$ were usually linear for $I / I_{0}>0.1$. A typical plot of primary data is shown in Fig. 2.

From the slope $S$ of such lines the total cross section $Q$ may be calculated, using the Rosin-Rabi ${ }^{2}$ equation ${ }^{15}$

$$
Q=2(\pi)^{\frac{1}{3}} J(z) \ln \left(I / I_{0}\right) / n_{1} d,
$$

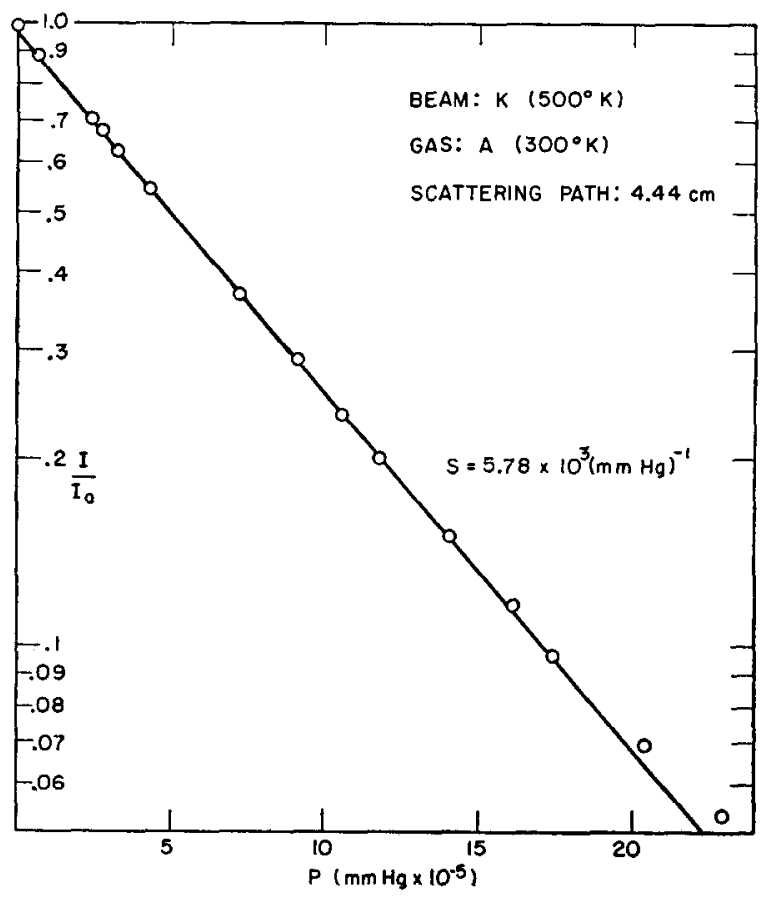

FIG. 2. Typical primary data.

${ }^{14} \mathrm{~A}$ pressure of $5 \times 10^{-4} \mathrm{~mm} \mathrm{Hg}$ in the scattering chamber yielded no detectable increase (i.e. $<2 \times 10^{-8} \mathrm{~mm} \mathrm{Hg}$ ) in the pressure in the detector chamber.

${ }_{15} \mathrm{As}$ pointed out by Rosin and Rabi, ${ }^{2}$ this equation is an approximation to the accurate one which involves a tedious numerical integration. Appendix I summarizes a number of calculations which show the validity of the approximation in the present case. 
where

$$
\begin{gathered}
J(z)=z^{2} \int_{0}^{\infty}\left[x^{5} / \psi(x)\right] \exp \left(-z x^{2}\right) d x \\
\psi(x)=x \exp \left(-x^{2}\right)+\left(2 x^{2}+1\right) \int_{0}^{x} \exp \left(-y^{2}\right) d y \\
z=m_{2} T_{1} / m_{1} T_{2} \text { and } x=v_{2} /\left(2 k T_{1} / m_{1}\right)^{\frac{1}{2}} .
\end{gathered}
$$

Here $Q$ is the cross section $\left(\mathrm{cm}^{2}\right) ; m_{1}, m_{2}$ are molecular masses of the scattering gas (1) and beam atoms (2); $T_{1}, T_{2}$ are temperatures $\left({ }^{\circ} \mathrm{K}\right)$ of the gas $(1)$ and beam (2); $v_{2}$ is the speed of the beam atom $\left(\mathrm{cm} \mathrm{sec}^{-1}\right) ; n_{1}=$ concentration of scattering gas (molecules $\mathrm{cm}^{-3}$ ) and $d$ is the scattering path length $(\mathrm{cm})$. For the present measurements $T_{1}=300^{\circ} \mathrm{K}$ and $d=4.44 \mathrm{~cm}$; thus

$$
Q=5.709 \times 10^{-19} J(z) S,
$$

with $S$ in units of $(\mathrm{mm} \mathrm{Hg})^{-1} . J(z)$ was obtained by graphical interpolation of Rosenberg's ${ }^{16}$ table.

It was found that values of $Q$ were not accurately reproducible over long intervals. In a one-year period the apparent cross section of $\mathrm{K}-\mathrm{A}$, for example, varied $\mathrm{d}^{17}$ over an extreme range of $\pm 10 \%$. However, the ratio of the cross sections of two gases was readily reproduced with a probable erorr of $\pm 3 \%$. Data are therefore reported in terms of relative cross sections $Q^{*}=Q_{12} / A_{\mathrm{A} 2}$ where $Q_{12}$ and $Q_{\mathrm{A} 2}$ are the total collision cross sections for beam 2 with gas 1 and with argon, respectively. All values of $Q^{*}$ represent an average of at least two measurements on different days. To minimize systematic errors due to possible adsorption "memory" effects, different sequences of molecules were used in replicate experiments.

\section{Materials}

All scattering gases were purified and characterized before use. Details of purification and physical properties are reported elsewhere, $\dagger$ together with data on the $\mathrm{K}$ and $\mathrm{Cs}$ used for the beams.

\section{RESULTS}

The absolute cross sections for $\mathrm{K}-\mathrm{A}$ and $\mathrm{Cs}-\mathbf{A}$ are subject to an overall uncertainty of perhaps $\pm 15 \%$, based on a consideration of the numerous systematic errors (including, e.g., the problem of the absolute value of the scattering gas pressure, the scattering

${ }_{16}$ P. Rosenberg, Phys. Rev, 61, 528 (1942).

17 The changes in $Q$ were probably due primarily to changes in resolution. The largest effects were noted when the slits were cleaned or reset. When the slits began to clog, $Q$ increased (presumably on account of the narrower beam); after cleaning the slits, $Q$ decreased. Improper beam alignment also led to decreased values of $Q$.
TABLE I. Comparison of $Q^{*}$ with literature data.

\begin{tabular}{llllc} 
& $\begin{array}{c}\text { Present } \\
\text { results }\end{array}$ & $\begin{array}{c}\text { Reference } \\
1\end{array}$ & $\begin{array}{c}\text { Reference } \\
2\end{array}$ & $\begin{array}{c}\text { Reference } \\
3\end{array}$ \\
\hline $\mathrm{K}-\mathrm{H}_{2}$ & 0.321 & 0.307 & 0.302 & 0.336 \\
$\mathrm{~K}-\mathrm{D}_{2}$ & 0.360 & & 0.393 & 0.430 \\
$\mathrm{~K}-\mathrm{He}$ & 0.292 & 0.283 & 0.284 & 0.291 \\
$\mathrm{~K}-\mathrm{Ne}$ & 0.40 & 0.45 & 0.45 & \\
$\mathrm{~K}-\mathrm{N}_{2}$ & 0.97 & 0.94 & 0.313 & \\
$\mathrm{Cs}-\mathrm{H}_{2}$ & 0.310 & & 0.383 & \\
$\mathrm{Cs}-\mathrm{D}_{2}$ & 0.380 & & 0.283 & \\
$\mathrm{Cs}-\mathrm{He}$ & 0.310 & & 0.50 & \\
$\mathrm{Cs}-\mathrm{Ne}$ & 0.44 & & 0 & \\
\hline
\end{tabular}

path length, and the influence of imperfect resolution upon the cross section). The results are as follows:

$\begin{array}{lrc} & Q_{\text {mean }}\left(\mathrm{A}^{2}\right) & Q_{\text {max }}\left(\mathrm{A}^{2}\right) \\ \mathrm{K}-\mathrm{A} & 734 & 767 \\ \mathrm{Cs}-\mathrm{A} & 857 & 895,\end{array}$

where $Q_{\text {mean }}$ represents the average of all observed values and $Q_{\max }$ is the largest observation. These differ significantly from previous results; e.g., Rosin and $\mathrm{Rabi}^{2}$ found $Q_{\mathrm{K}-\mathrm{A}}$ and $Q_{\mathrm{Cs}-\mathrm{A}}$ to be 580 and $572 \mathrm{~A}^{2}$, respectively. The resolution $\left(30^{\prime \prime}\right)$ of the present apparatus is only slightly better than that $\left(c a 1^{\prime}\right)$ of the earlier investigators; ${ }^{2}$ the origin of the discrepancy is not clear. However, the relative cross sections are in fair agreement with previous results. Table I shows a comparison of present values of $Q^{*}$ with those from three investigations in which results with argon were reported.

The results for all molecules studied are listed in Table II following a description of the procedure used for the theoretical estimation of $Q^{*}$.

\section{THEORETICAL ESTIMATION OF $Q^{*}$}

Massey and Buckingham ${ }^{18}$ have applied the MasseyMohr theory to data ${ }^{2}$ on the scattering of alkali beams by $\mathrm{He}, \mathrm{Ne}$, and $\mathrm{A}$. From the experimental cross sections they evaluated the attractive potential constant defined on the basis of an inverse sixth-power potential

$$
V(r)=-C / r^{6},
$$

and compared these values of $C$ with theoretical estimates based on the Hellmann ${ }^{19}$ formula for the London dispersion force. The discrepancies between calculated and observed values of $C$ ranged from $5-70 \%$.

For the potential function of Eq. (3), the MasseyMohr expression for the total elastic cross section becomes

$$
Q=b\left(C / v_{r}\right)^{2 / 5},
$$

where $v_{r}$ is the average relative velocity of the colliding

\footnotetext{
${ }^{18}$ H. S. Massey and R. A. Buckingham, Nature 138, 77 (1936).

${ }^{19}$ H. Hellmann, Acta Physicochim. U.R.S.S. 2, 273 (1935).
} 
TABLE II. Summary of results for $\mathrm{K}$.

\begin{tabular}{|c|c|c|c|c|c|c|c|}
\hline Molecule & $\mu$ & $\alpha$ & $C_{\text {disp }}$ & $C_{\mathrm{ind}}$ & $10^{-5} \bar{v}_{r}$ & $Q_{\mathrm{calo}}{ }^{*}$ & $Q_{\text {obs }}{ }^{*}$ \\
\hline \multicolumn{8}{|l|}{ A. Inert gases. } \\
\hline $\begin{array}{l}\mathrm{He} \\
\mathrm{Ne} \\
\mathrm{A} \\
\mathrm{Kr} \\
\mathrm{Xe}\end{array}$ & $\begin{array}{l}0 \\
0 \\
0 \\
0 \\
0\end{array}$ & $\begin{array}{l}0.206 \\
0.408 \\
1.64 \\
2.48 \\
4.02\end{array}$ & $\begin{array}{l}28.7 \\
57.7 \\
223 \\
333 \\
526\end{array}$ & & $\begin{array}{l}1.396 \\
0.826 \\
0.727 \\
0.669 \\
0.649\end{array}$ & $\begin{array}{c}0.339 \\
0.553 \\
(1.00) \\
1.21 \\
1.47\end{array}$ & $\begin{array}{c}0.292 \\
0.400 \\
(1.00) \\
1.26 \\
1.45\end{array}$ \\
\hline
\end{tabular}

B. Diatomic molecules.

$\begin{array}{lllllll}\mathrm{H}_{2} & 0 & 0.806 & 107 & & 1.874 & 0.509 \\ \mathrm{D}_{2} & 0 & 0.796 & 105 & & 1.393 & 0.571 \\ \mathrm{O}_{2} & 0 & 1.57 & 217 & & 0.753 & 0.974 \\ \mathrm{~N}_{2} & 0 & 1.74 & 238 & & 0.771 & 0.960 \\ \mathrm{CO} & 0.1 & 1.94 & 264 & 1.00 & 0.97 \\ \mathrm{NO} & 0.16 & 1.70 & 234 & 36 & 0.771 & 1.05 \\ \mathrm{HCl} & 1.03 & 2.58 & 344 & 36 & 0.762 & 1.00 \\ \mathrm{HBr} & 0.79 & 3.49 & 460 & 21 & 0.671 & 1.23 \\ \end{array}$

C. Triatomic molecules.

$\begin{array}{ll}\mathrm{CO}_{2} & 0 \\ \mathrm{CS}_{2} & 0 \\ \mathrm{H}_{2} \mathrm{O} & 1.84 \\ \mathrm{~N}_{2} \mathrm{O} & 0.17 \\ \mathrm{H}_{2} \mathrm{~S} & 1.02 \\ \mathrm{SO}_{2} & 1.62 \\ \text { D. Spherical top molecules. }\end{array}$

$\mathrm{CF}_{4}$
$\mathrm{SiF}_{4}$
$\mathrm{SF}_{6}$
$\mathrm{CCl}_{4}$
$\mathrm{SiCl}_{4}$
$\mathrm{SnCl}_{4}$

E. Hydrocarbons.

$\mathrm{CH}_{4}$
$\mathrm{C}_{2} \mathrm{H}_{4}$
$\mathrm{C}_{2} \mathrm{H}_{6}$
$\mathrm{C}_{3} \mathrm{H}_{6}$
$\mathrm{C}_{3} \mathrm{H}_{8}$
trans- $\mathrm{C}_{4} \mathrm{H}_{8}-2$
$n-\mathrm{C}_{4} \mathrm{H}_{10}$
$i-\mathrm{C}_{4} \mathrm{H}_{10}$
cis $-\mathrm{C}_{4} \mathrm{H}_{8}-2$
$\mathrm{C}_{4} \mathrm{H}_{8}-1$
$i-\mathrm{C}_{4} \mathrm{H}_{8}$
cyclo- $\mathrm{C}_{5} \mathrm{H}_{10}$
$n-\mathrm{C}_{5} \mathrm{H}_{12}$
$\mathrm{C}_{6} \mathrm{H}_{6}$
cyclo
$n-\mathrm{C}_{6} \mathrm{H}_{12}$
$n-\mathrm{C}_{6} \mathrm{H}_{14}$
$\mathrm{C}_{6} \mathrm{H}_{5} \mathrm{CH}_{3}$

$\begin{array}{lr}0 & 2.56 \\ 0 & 4.10 \\ 0 & 4.39 \\ 0.34 & 6.04 \\ 0 & 6.23 \\ 0 & 7.87 \\ 0 & 8.00 \\ 0 & 8.00 \\ 0 & 7.87 \\ 0.37 & 7.82 \\ 0.49 & 7.87 \\ 0 & 8.94 \\ 0 & 9.77 \\ 0 & 9.99 \\ 0 & 10.75 \\ 0 & 11.59 \\ 0.37 & 11.81\end{array}$

F. Chlorinated $\mathrm{C}_{2}$ hydrocarbons.

$\begin{array}{llr}\mathrm{C}_{2} \mathrm{H}_{5} \mathrm{Cl} & 2.02 & 6.30 \\ 1,2-\mathrm{C}_{2} \mathrm{H}_{4} \mathrm{Cl}_{2} & 1.12 & 8.12 \\ 1,1-\mathrm{C}_{2} \mathrm{H}_{4} \mathrm{Cl}_{2} & 2.07 & 8.16 \\ \mathrm{C}_{2} \mathrm{HCl}_{3} & 0.94 & 9.55 \\ 1,1,2-\mathrm{C}_{2} \mathrm{H}_{3} \mathrm{Cl}_{3} & 1.25 & 9.97 \\ 1,1,1-\mathrm{C}_{2} \mathrm{H}_{3} \mathrm{Cl}_{3} & 1.79 & 10.12 \\ \mathrm{C}_{2} \mathrm{Cl}_{4} & 0 & 11.61 \\ s-\mathrm{C}_{2} \mathrm{H}_{2} \mathrm{Cl}_{4} & 1.36 & 11.84\end{array}$

G. $n$-Alkyl bromides.

$\begin{array}{llrr}\mathrm{CH}_{3} \mathrm{Br} & 1.79 & 5.44 & 72 \\ \mathrm{C}_{2} \mathrm{H}_{5} \mathrm{Br} & 2.02 & 7.33 & 97 \\ \mathrm{C}_{3} \mathrm{H}_{7} \mathrm{Br} & 2.04 & 9.13 & 121 \\ \mathrm{C}_{4} \mathrm{H}_{9} \mathrm{Br} & 2.04 & 10.93 & 1458 \\ \mathrm{C}_{6} \mathrm{H}_{13} \mathrm{Br} & 1.97 & 14.51 & 1939 \\ \mathrm{C}_{8} \mathrm{H}_{17} \mathrm{Br} & 1.96 & 18.15 & 242\end{array}$

$\begin{array}{rr}2.59 & 356 \\ 8.08 & 1057 \\ 1.45 & 199 \\ 2.92 & 399 \\ 3.61 & 475 \\ 3.78 & 514\end{array}$

$2.82 \quad 394$

$3.32 \quad 462$

$4.48 \quad 625$

$\begin{array}{ll}10.24 & 1369 \\ 11.27 & 1501\end{array}$

13.71 1809

$2.56 \quad 342$

547

587
806

835

1051

1073

1072

1051
1046

1051

1200

1310

1335

1442

1554

1578
843
1088
1092
1278
1335
1355
1553
1585

0.717
0.674
0.848
0.717
0.745
0.686

1.21

1.08

1.27

1.38

1.80

0.97

1.28

1.31

89

0.686

1.52

1.50

$\begin{array}{lll}0.666 & 1.30 & 1.32 \\ 0.658 & 1.39 & 1.40 \\ 0.645 & 1.58 & 1.54 \\ 0.644 & 2.17 & 2.18 \\ 0.641 & 2.25 & 2.19 \\ 0.631 & 2.44 & 2.28\end{array}$

0.631

2.19
2.28

32

1.40

1.54

18

0.97

1.30

1.31

1.57

1.61

1.79

1.80

1.80

1.81

1.82

1.82

2.00

2.03

1.98

2.05

2.22

5

0.669

0.667

2.26

0.685

0.661
0.661

0.661
0.649

0.648

0.648
0.642

0.641

2.25

2.27

$\begin{array}{rlll}139 & 0.685 & 1.85 & 1.78 \\ 43 & 0.661 & 1.99 & 2.01 \\ 146 & 0.661 & 2.06 & 2.03 \\ 30 & 0.649 & 2.12 & 2.11 \\ 53 & 0.648 & 2.17 & 2.21 \\ 109 & 0.648 & 2.22 & 2.20 \\ & 0.642 & 2.28 & 2.30 \\ 63 & 0.641 & 2.34 & 2.34\end{array}$

$\begin{array}{rllll}722 & 109 & 0.663 & 1.75 & 1.77 \\ 975 & 139 & 0.656 & 1.98 & 1.93 \\ 1216 & 141 & 0.651 & 2.15 & 2.16 \\ 1458 & 141 & 0.648 & 2.30 & 2.28 \\ 1939 & 132 & 0.642 & 2.56 & 2.56 \\ 2427 & 131 & 0.638 & 2.79 & 2.80\end{array}$


TABLE II.-Continued.

\begin{tabular}{|c|c|c|c|c|c|c|c|}
\hline Molecule & $\mu$ & $\alpha$ & $C_{\mathrm{disp}}$ & $C_{\text {ind }}$ & $10^{-5} \bar{v}_{r}$ & $Q_{\mathrm{ea} 10} *$ & $Q_{\text {obs }}{ }^{*}$ \\
\hline \multicolumn{8}{|c|}{ H. Halomethanes. } \\
\hline $\begin{array}{l}\mathrm{CH}_{3} \mathrm{~F} \\
\mathrm{CH}_{2} \mathrm{~F}_{2} \\
\mathrm{CHF}_{3} \\
\mathrm{CH}_{3} \mathrm{Cl} \\
\mathrm{CH}_{2} \mathrm{Cl}_{2} \\
\mathrm{CHCl}_{3} \\
\mathrm{CCl}_{4} \\
\mathrm{CH}_{3} \mathrm{Br} \\
\mathrm{CH}_{3} \mathrm{I} \\
\mathrm{CF}_{4} \\
\mathrm{CClF}_{3} \\
\mathrm{CBrF}_{3} \\
\mathrm{CH}_{2} \mathrm{FCl} \\
\mathrm{CHF}_{2} \mathrm{Cl} \\
\mathrm{CHFCl}_{2} \\
\mathrm{CF}_{2} \mathrm{Cl}_{2} \\
\mathrm{CH}_{2} \mathrm{ClBr}_{2} \\
\mathrm{CHFClBr} \mathrm{FCl}\end{array}$ & $\begin{array}{c}1.79 \\
1.96 \\
1.64 \\
1.87 \\
1.62 \\
1.02 \\
\text { Listed in D. } \\
\text { Listed in G. } \\
1.65 \\
\text { Listed in D. } \\
0.46 \\
0.65 \\
1.79 \\
1.29 \\
1.29 \\
0.51 \\
1.53 \\
1.32\end{array}$ & $\begin{array}{l}7.29 \\
4.65 \\
5.65 \\
4.51 \\
4.44 \\
6.39 \\
6.34 \\
7.27 \\
7.44\end{array}$ & $\begin{array}{r}640 \\
774 \\
611 \\
608 \\
865 \\
865 \\
967 \\
1000\end{array}$ & $\begin{array}{r}93 \\
\\
7 \\
14 \\
109 \\
57 \\
57 \\
9 \\
80 \\
59\end{array}$ & $\begin{array}{l}0.745 \\
0.702 \\
0.680 \\
0.704 \\
0.668 \\
0.653 \\
0.644 \\
0.663 \\
0.646 \\
0.666 \\
0.658 \\
0.645 \\
0.681 \\
0.667 \\
0.659 \\
0.652 \\
0.650 \\
0.645\end{array}$ & $\begin{array}{l}1.32 \\
1.40 \\
1.39 \\
1.61 \\
1.83 \\
2.01 \\
2.17 \\
1.75 \\
1.94 \\
1.30 \\
1.59 \\
1.74 \\
1.64 \\
1.60 \\
1.83 \\
1.80 \\
1.94 \\
1.95\end{array}$ & $\begin{array}{l}1.27 \\
1.34 \\
1.37 \\
1.60 \\
1.83 \\
2.01 \\
2.18 \\
1.77 \\
1.90 \\
1.32 \\
1.58 \\
1.72 \\
1.57 \\
1.58 \\
1.87 \\
1.81 \\
1.97 \\
2.10\end{array}$ \\
\hline \multicolumn{8}{|c|}{ I. Miscellaneous molecules. } \\
\hline $\begin{array}{l}\mathrm{NH}_{3} \\
\mathrm{H}_{2} \mathrm{CO} \\
\mathrm{CH}_{3} \mathrm{OH} \\
\mathrm{CH}_{3} \mathrm{NH}_{2} \\
\left(\mathrm{CH}_{3}\right)_{2} \mathrm{CO} \\
\mathrm{C}_{3} \mathrm{H}_{5} \mathrm{Cl} \\
\mathrm{C}_{6} \mathrm{H}_{5} \mathrm{Br}\end{array}$ & $\begin{array}{l}1.47 \\
2.31 \\
1.70 \\
1.27 \\
2.85 \\
2.02 \\
1.70\end{array}$ & $\begin{array}{r}2.16 \\
2.81 \\
3.25 \\
3.92 \\
6.11 \\
7.84 \\
12.89\end{array}$ & $\begin{array}{r}291 \\
381 \\
440 \\
527 \\
826 \\
1048 \\
1716\end{array}$ & $\begin{array}{r}73 \\
181 \\
98 \\
55 \\
276 \\
139 \\
98\end{array}$ & $\begin{array}{l}0.860 \\
0.761 \\
0.753 \\
0.757 \\
0.693 \\
0.674 \\
0.643\end{array}$ & $\begin{array}{l}1.14 \\
1.42 \\
1.40 \\
1.44 \\
1.93 \\
2.01 \\
2.43\end{array}$ & $\begin{array}{l}0.99 \\
1.28 \\
1.38 \\
1.28 \\
1.89 \\
1.97 \\
2.32\end{array}$ \\
\hline
\end{tabular}

atoms $\left(\mathrm{cm} \mathrm{sec}^{-1}\right)$, and $b=4.662 \times 10^{11}$ for $C$ in units of erg $\mathrm{cm}^{6}$. For the present case of beam scattering by molecules one requires an estimate of $C$.

The long-range molecular interactions may be divided into three types: (a) direct dipole-dipole, (b) dipoleinduced dipole and (c) induced dipole-induced dipole (or London dispersion) interactions. To a first approximation all of these are expressible in terms of an inverse sixth-power dependence on the intermolecular distance (for large $r$ ). Thus in Eq. (3), $C=C_{d-d}+$ $C_{\text {ind }}+C_{\text {disp }}$, where

$$
\begin{gathered}
C_{\mathrm{d}-\mathrm{d}}=2 \mu_{1}^{2} \mu_{2}^{2} / 3 k T, \\
C_{\mathrm{ind}}=\alpha_{2} \mu_{1}^{2}+\alpha_{1} \mu_{2}^{2},
\end{gathered}
$$

and

$$
C_{\mathrm{disp}}=\frac{3 e \hbar}{2\left(m_{e}\right)^{\frac{1}{2}}} \frac{\alpha_{1} \alpha_{2}}{\left[\left(\alpha_{1} / N_{1}\right)^{\frac{1}{2}}+\left(\alpha_{2} / N_{2}\right)^{\frac{1}{2}}\right]}
$$

Here $\mu, \alpha$, and $N$ refer, respectively, to the dipole moment, the polarizability, and the number of outer shell electrons of each molecule: $m_{e}$ and $e$ represent the electronic mass and charge, and $\hbar$ and $k$ have their usual meaning. For the molecular beam case Eq. (5)

${ }^{20}$ W. Keesom, Physik. Z. 22, 129 (1921).

${ }^{21}$ P. Debye, Physik. Z. 22, 302 (1921).

${ }_{22}$ F. London, Z. Physik 63, 245 (1930).

${ }^{23}$ J. Slater and J. Kirkwood, Phys. Rev. 37, 682 (1931). must be somewhat modified. ${ }^{24}$ With reference to the present experiments dealing with $\mathrm{K}$ and $\mathrm{Cs}$ beams, $C_{\mathrm{d}-\mathrm{d}}=0$; Eqs. (6) and (7) become

and

$$
C_{\text {ind }}=D \mu_{1}^{2} \text {, }
$$

$$
C_{\mathrm{dikp}}=E \alpha_{1} /\left[F+\left(\alpha_{1} / N_{1}\right)^{\frac{1}{2}}\right] \text {, }
$$

with $\mu_{1}$ in Debyes and $\alpha_{1}$ in $\mathrm{A}^{3}$. Evaluating ${ }^{25}$ the constants to give $C$ in units of $10^{-60} \mathrm{erg} \mathrm{cm}^{6}$, one obtains

$\begin{array}{lcrc} & D & E & F \\ \mathrm{~K} & 34.0 & 855.8 & 5.832 \\ \mathrm{Cs} & 42.0 & 1057.1 & 6.480 .\end{array}$

It is not within the scope of the present paper to offer a critique of the validity of Eq. (7); its obvious advantage is that it requires only a knowledge of

${ }^{24}$ If $T_{1}$ and $T_{2}$ are the temperatures $\left({ }^{\circ} \mathrm{K}\right)$ of the different species, the appropriate substitution $\dagger$ would be

$$
T=2 T_{1} T_{2} /\left(T_{1}+T_{2}\right) \text {. }
$$

It is to be noted that Eq. (5) is valid only for

$$
r \gg r_{\min }=\left(\mu_{1} \mu_{2} / k T\right)^{1 / 3} \text {; }
$$

thus for $\mu_{1}=\mu_{2}=1 D$ and $T=300^{\circ} \mathrm{K}, r_{\mathrm{min}}=2.9 \mathrm{~A}$; for $\mu_{1}=1 D$ and $\mu_{2}=10 D, r_{\min }=6.2 \mathrm{~A}$.

25 The polarizabilities of $\mathrm{K}$ and $\mathrm{Cs}$ were taken to be 34.0 and $42.0 \mathrm{~A}^{3}$, respectively [H. Scheffers and J. Stark, Physik. Z. 35, 625 (1934) ]. The units of $\mu_{1}$ and $\alpha_{1}$ are debyes and $A^{3}$, respectively. $N$ is obtained by summing the periodic table group numbers for each constituent atom in the scattering molecule $(N=8$ for the noble gases, except for $\mathrm{He}$, where $N=2$ ). 
TABLE III. Summary of results for Cs.

\begin{tabular}{|c|c|c|c|c|c|c|c|}
\hline Molecule & $\mu$ & $\alpha$ & $C_{\text {disp }}$ & $C_{\text {ind }}$ & $10^{-5} \bar{v}_{r}$ & $Q_{\mathrm{eqle}}{ }^{*}$ & $Q_{\mathrm{obs}}{ }^{*}$ \\
\hline $\begin{array}{l}\mathrm{He} \\
\mathrm{Ne} \\
\mathrm{A} \\
\mathrm{Kr} \\
\mathrm{Xe}\end{array}$ & $\begin{array}{l}0 \\
0 \\
0 \\
0 \\
0\end{array}$ & $\begin{array}{l}0.206 \\
0.408 \\
1.64 \\
2.49 \\
4.02\end{array}$ & $\begin{array}{c}32.0 \\
64.3 \\
250 \\
373 \\
591\end{array}$ & & $\begin{array}{l}1.297 \\
0.641 \\
0.506 \\
0.416 \\
0.382\end{array}$ & $\begin{array}{c}0.301 \\
0.528 \\
(1.00) \\
1.27 \\
1.58\end{array}$ & $\begin{array}{c}0.310 \\
0.440 \\
(1.00) \\
1.28 \\
1.58\end{array}$ \\
\hline $\begin{array}{l}\mathrm{H}_{2} \\
\mathrm{D}_{2} \\
\mathrm{~N}_{2}\end{array}$ & $\begin{array}{l}0 \\
0 \\
0\end{array}$ & $\begin{array}{l}0.806 \\
0.796 \\
1.74\end{array}$ & $\begin{array}{l}120 \\
118 \\
267\end{array}$ & & $\begin{array}{l}1.802 \\
1.293 \\
0.568\end{array}$ & $\begin{array}{l}0.448 \\
0.509 \\
0.98\end{array}$ & $\begin{array}{l}0.310 \\
0.380 \\
0.95\end{array}$ \\
\hline $\begin{array}{l}\mathrm{CO}_{2} \\
\mathrm{H}_{2} \mathrm{O}\end{array}$ & $\begin{array}{l}0 \\
1.84\end{array}$ & $\begin{array}{l}2.59 \\
1.45\end{array}$ & $\begin{array}{l}398 \\
223\end{array}$ & 142 & $\begin{array}{l}0.491 \\
0.670\end{array}$ & $\begin{array}{l}1.22 \\
1.04\end{array}$ & $\begin{array}{l}1.21 \\
1.03\end{array}$ \\
\hline $\begin{array}{l}\mathrm{CH}_{4} \\
\mathrm{CF}_{4} \\
\mathrm{SF}_{6} \\
\mathrm{SiCl}_{4}\end{array}$ & $\begin{array}{l}0 \\
0 \\
0 \\
0\end{array}$ & $\begin{array}{r}2.56 \\
2.82 \\
4.48 \\
11.27\end{array}$ & $\begin{array}{r}383 \\
440 \\
698 \\
1684\end{array}$ & & $\begin{array}{l}0.701 \\
0.412 \\
0.376 \\
0.368\end{array}$ & $\begin{array}{l}1.04 \\
1.36 \\
1.70 \\
2.44\end{array}$ & $\begin{array}{l}0.98 \\
1.44 \\
1.72 \\
2.30\end{array}$ \\
\hline $\begin{array}{l}\mathrm{H}_{2} \mathrm{CO} \\
\left(\mathrm{CH}_{3}\right)_{2} \mathrm{CO}\end{array}$ & $\begin{array}{l}2.31 \\
2.85\end{array}$ & $\begin{array}{l}2.81 \\
6.11\end{array}$ & $\begin{array}{l}426 \\
925\end{array}$ & $\begin{array}{l}224 \\
341\end{array}$ & $\begin{array}{l}0.555 \\
0.454\end{array}$ & $\begin{array}{l}1.41 \\
2.00\end{array}$ & $\begin{array}{l}1.30 \\
1.87\end{array}$ \\
\hline
\end{tabular}

polarizability. Massey and Buckingham ${ }^{18}$ used Hellmann's more complex equation; however this results ${ }^{19}$ in no appreciable change in the numerical values for the energy. The denominator of Eq. (7) is nearly constant for all scattering gases with $\mathrm{K}$ and $\mathrm{Cs}$ (since $\alpha_{2} / N_{2}$ is relatively large); thus $C_{\mathrm{d} \text { i } a p}$ is approximately proportional to the polarizability of the scattering molecule. The present results are therefore insensitive to the form of the denominator. ${ }^{26}$

Polarizabilities were obtained from literature data, usually by extrapolating molar refractions from the visible region to $\lambda=\infty$ to obtain $P_{E}$; then $\alpha\left(\mathrm{A}^{3}\right)=$ $0.3963 P_{E}(\mathrm{cc})$. Tables II and III summarize the values of $\alpha$ and $\mu$ employed $\dagger$ in the present calculations.

For the evaluation of the average relative velocity Massey and Buckingham ${ }^{18}$ used $^{27}$ a spherical average of $v^{-2 / 5}$, in terms of average Maxwellian velocities for the gas and beam particles, respectively. In the present work $\bar{v}_{r}$ was obtained by averaging all relative velocities of the gas and the beam molecules. The resulting equation [see Appendix II, Eq. (e)] gives values which differ, however, by less than 5\% from those obtained using average velocities for gas and beam particles together with the standard formulas ${ }^{28}$ for the relative velocity:

$$
\begin{array}{lll}
\bar{v}_{r}=\bar{v}_{2}+\left(\bar{v}_{1}^{2} / 3 \bar{v}_{2}\right) & \text { for } & \bar{v}_{2}>\bar{v}_{1} \\
\bar{v}_{r}=\bar{v}_{1}+\left(\bar{v}_{2}{ }^{2} / 3 \bar{v}_{1}\right) & \text { for } & \bar{v}_{1}>\bar{v}_{2}
\end{array}
$$

where

$$
\bar{v}_{1}=\left(8 k T_{1} / \pi m_{1}\right)^{\frac{1}{2}} \quad \text { and } \quad \bar{v}_{2}=\left(9 \pi k T_{2} / 8 m_{2}\right)^{\frac{1}{2}},
$$

${ }^{26}$ The same conclusion results from substituting for the denominator a term proportional to $1 / I_{1}+1 / I_{2}$ (where the $I$ 's are the first ionization potentials of the two species).

${ }^{27}$ R. A. Buckingham (private communication), March 17, 1959

${ }^{28}$ See, for example, L. Loeb, Kinetic Theory of Gases (McGrawHill Book Company, Inc., New York, 1934), p. 95. respectively. Since $Q$ [according to Eq. (4)] is relatively insensitive to $v_{r}$, no important errors result in any case. Tables II and III summarize the results of all experiments and calculations for beams of $\mathrm{K}$ and Cs at $500^{\circ} \mathrm{K}$ and $450^{\circ} \mathrm{K}$, respectively. The columns list (for each scattering gas) $\mu(\mathrm{D}), \alpha\left(\mathrm{A}^{3}\right), C_{\text {disp }}$ and $C_{\text {ind }}\left(10^{-60} \mathrm{erg} \mathrm{cm}^{6}\right), \bar{v}_{r}\left(\mathrm{~cm} \mathrm{sec}^{-1}\right), Q_{\mathrm{calo}}{ }^{*}$ and $Q_{\mathrm{obs}}{ }^{*}$.

\section{DISCUSSION OF RESULTS}

It is of interest to compare absolute values before proceeding to a discussion of relative cross sections. The results are summarized in Table IV.

The experimental values are significantly higher than $Q_{\text {calc }}$. The very high-resolution $\left(5^{\prime \prime}\right)$ experiments of Estermann, Foner, and Stern ${ }^{10}$ on the cross section for $\mathrm{Cs}-\mathrm{He}$ yielded experimental values still higher than the present results. Recent high-resolution experiments of Pauly ${ }^{29}$ gave cross sections for $\mathrm{K}-\mathrm{N}_{2}$ and $\mathrm{Cs}-\mathrm{N}_{2}$ of 679 and $908 \mathrm{~A}^{2}$, respectively, in fair agreement with the present values.

From an experimental viewpoint the question of resolution certainly needs further attention; at the same time the theoretical estimation of $C_{\mathrm{d} \text { isp }}$ is also in need of refinement.

As seen in Tables II and III, relative cross sections $Q_{\mathrm{cslo}}{ }^{*}$ and $Q_{\mathrm{obs}}{ }^{*}$ are in good agreement generally. Points of interest are noted below. In Appendix III a brief theoretical correlation of the data of two other

\begin{tabular}{|c|c|c|c|c|}
\hline & $\left(Q_{\text {obs }}\right)_{\text {mean }}$ & $\begin{array}{l}\text { Exptl. ratio } \\
\mathrm{K}-\mathrm{A} / \mathrm{Cs}-\mathrm{A}\end{array}$ & $Q_{\text {cale }}$ & $\underset{\mathrm{K}-\mathrm{A} / \mathrm{Cs}-\mathrm{A}}{\text { Calc. ratio }}$ \\
\hline $\begin{array}{l}\mathrm{K}-\mathrm{A} \\
\mathrm{Cs}-\mathrm{A}\end{array}$ & $\left.\begin{array}{l}734 \\
857\end{array}\right\}$ & 0.86 & $\left.\begin{array}{l}461 \\
558\end{array}\right\}$ & 0.83 \\
\hline
\end{tabular}
investigations is given.

TABLE IV. Comparison of absolute cross sections $\left(A^{2}\right)$.

${ }^{29}$ H. Pauly, Z. angew. Phys. 9, 600 (1957). 


\section{(A) Inert Gases}

The observed values of $Q^{*}$ are in good agreement with $Q_{\text {oale }}{ }^{*}$ (for both $\mathrm{K}$ and $\mathrm{Cs}$ ), except for $\mathrm{Ne}$, for which the $Q_{\mathrm{calc}}{ }^{*}$ is appreciably higher than $Q_{\mathrm{obs}}{ }^{*}$. The present value of $Q_{\mathrm{obs}}{ }^{*}$ for Ne is also lower than results obtained by previous workers (Table I), but even these are lower than $Q_{\mathrm{calc}_{\mathrm{c}}} *$. No explanation of this discrepancy is offered.$^{30}$

\section{(B) Diatomic Molecules}

Good agreement between $Q_{\mathrm{obs}} *$ and $Q_{\mathrm{os} \text { lo }} *$ is noted for both $\mathrm{K}$ and $\mathrm{Cs}$ beams, with all scattering molecules except $\mathrm{H}_{2}$ and $\mathrm{D}_{2}$, where $Q_{\mathrm{calc}}{ }^{*}$ is seen to be considerably higher than $Q_{\text {obs }}{ }^{*}$. It may be noted, however, that the ratios of the cross sections of $\mathrm{H}_{2}$ and $\mathrm{D}_{2}$ for both $\mathrm{K}$ and $\mathrm{Cs}$ agree closely with the calculated ratios. The potential constants of $\mathrm{H}_{2}$ and $\mathrm{D}_{2}$ are virtually identical, so $C_{\mathrm{oalo}}{ }^{*}$ is nearly the same for both molecules. Thus the difference in the cross sections is explainable entirely in terms of the relative velocity factor in Eq. (4).

\section{(C) Triatomic Molecules}

$Q_{\text {obs }}{ }^{*}$ for $\mathrm{H}_{2} \mathrm{O}$ is considerably lower than $Q_{\text {calc }}{ }^{*}$ with $\mathrm{K}$. Because of experimental difficulties with $\mathrm{H}_{2} \mathrm{O}$ the experimental results should be accepted with caution.

\section{(D) Spherical Top Molecules}

Good agreement of observed and calculated $Q^{*}$ 's is found for all spherical top molecules. Only for $\mathrm{SnCl}_{4}$ is the discrepancy greater than the $\pm 3 \%$ uncertainty in $Q_{\mathrm{obs}}{ }^{*}$.

\section{(E) Hydrocarbons}

A comparison of $Q_{\mathrm{obs}}{ }^{*}$ and $Q_{\mathrm{cslc}}{ }^{*}$ for the $n$-alkanes is shown in Fig. 3. The deviations are greatest for the lighter hydrocarbons. Reference to Table II shows no significant differentiation between isomers of hydrocarbons.

\section{(F) Chlorinated $\mathrm{C}_{2}$ Hydrocarbons}

Good agreement between $Q_{\mathrm{obs}}{ }^{*}$ and $Q_{\mathrm{ealc}}{ }^{*}$ is noted. Again, isomers are seen to be experimentally indistinguishable.

\section{(G) n-Alkyl Bromides}

The results are shown in Fig. 3. Agreement is good throughout.

${ }^{30}$ Any impurity in the neon would lead to a greater apparent cross section, since $\mathrm{Ne}$ is the least effective molecule for beam scattering of those studied. Molecules with lower cross section are known, but these have smaller mass (and thus higher speeds), making them more efficient scatterers.

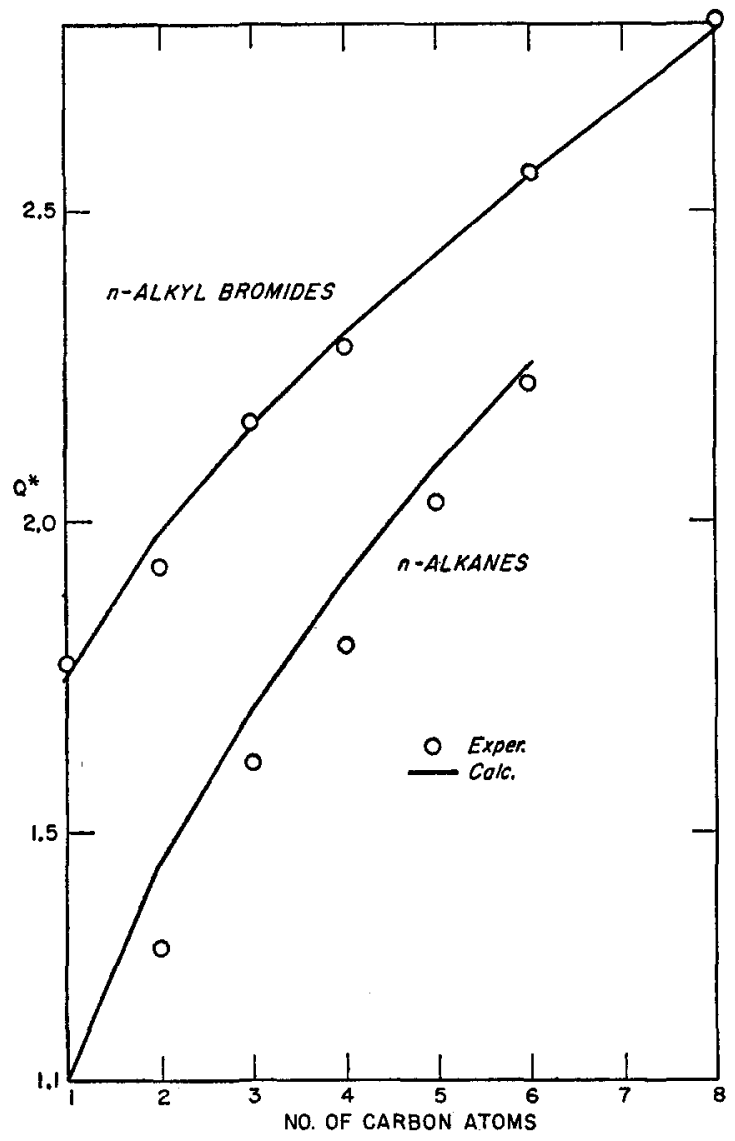

FIG. 3. Comparison of observed and calculated $Q^{*}$. K Beam.

\section{(H) Halomethanes}

Most of the results are plotted in Fig. 4. Agreement is generally good. The fluoromethane series illustrates the effect of the induction term, $C_{\text {ind. }}$. The polarizability increases only slightly in the series from $\mathrm{CH}_{4}$ to $\mathrm{CF}_{4}$. $\mathrm{CH}_{4}$ and $\mathrm{CF}_{4}$ are non-polar, while the intermediate compounds are polar, giving rise to a $C_{\text {ind }}$ term. A maximum in the cross section is thus found for $\mathrm{CHF}_{3}$. The analogous effect in the chloride series is not observable because the small induction term is masked by the large effect of the polarizability increase.

\section{(I) Miscellaneous Molecules}

Fair agreement is noted for most cases. However, apparent cross sections for $\mathrm{NH}_{3}, \mathrm{CH}_{3} \mathrm{NH}_{2}$, and $\mathrm{CH}_{2} \mathrm{O}$ are lower than $Q_{c a l o}{ }^{*}$. Part of the discrepancy may be due to experimental difficulty (similar to the case of $\mathrm{H}_{2} \mathrm{O}$ ).

\section{SUMMARY OF DEVIATIONS}

Of the molecules studied with $\mathrm{K}$ and $\mathrm{Cs}$ beams, $57 \%$ showed deviations (calculated $v s$ observed) less than $\pm 3 \%$ (the estimated experimental uncertainty). For $18 \%$ the deviations were from $\pm 3 \%$ to $\pm 6 \%$; for $12 \%$ the range was from \pm 6 to $\pm 10 \%$. For $13 \%$ 


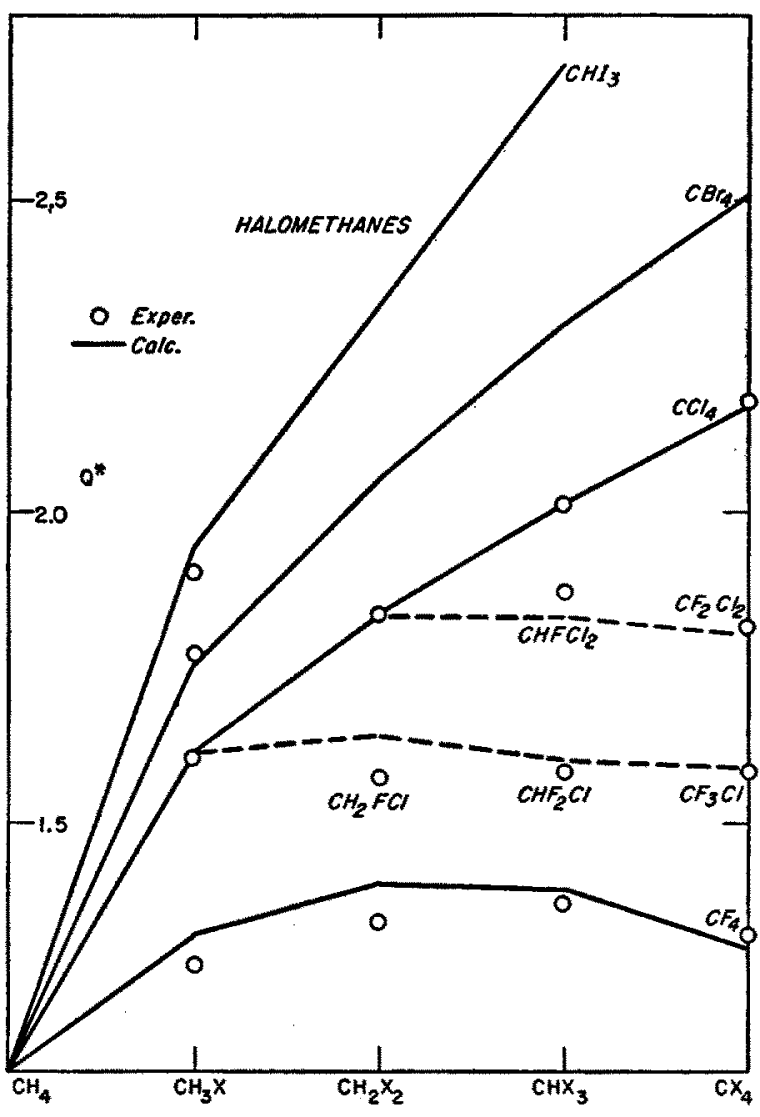

FIG. 4. Comparison of observed and calculated $Q^{*}$. K Beam.

deviations were greater than $\pm 10 \%$. Most of the large discrepancies occur with the relatively low molecular weight molecules.

\section{CONCLUSIONS}

It appears that (1) the principal contribution to the total cross section is that due to elastic scattering, (2) the Massey-Mohr approach represents a sound theoretical basis for discussion of the elastic scattering cross sections, (3) studies of elastic scattering give a rather direct measure of the long-range intermolecular attractive forces and (4) the Slater-Kirkwood approximation for the London force and the Debye equation for the induction force are sufficiently accurate to make useful predictions of potential constants, at least on a relative basis.

\section{ACKNOWLEDGMENTS}

The authors appreciate the technical assistance of Miss Ruth A. Peereboom. Thanks are due Dr. S. Datz, Dr. H. U. Hostettler, Dr. R. A. Marcus, and Dr. G. A. Miller for a number of valuable discussions.

The authors are grateful for the financial support of the Alfred P. Sloan Foundation and the U. S. Atomic
Energy Commission, Division of Research, Contract AT(11-1)-321.

\section{APPENDIX I. ACCURACY OF APPROXIMATION FORMULA [EQ. (1)] FOR $Q$}

A number of values of the transmittance $I / I_{0}$ have been $\dagger$ back-calculated using both the approximate formula [Eq. (1)] and the "exact formula" of Rosin and Rabi. ${ }^{2}$ The numerical integrations were carried out using an IBM 650 computer. Values were obtained for $\mathrm{K}\left(500^{\circ} \mathrm{K}\right)$ scattering in $\mathrm{H}_{2}, \mathrm{He}, \mathrm{CH}_{4}, \mathrm{~A}$, and $\mathrm{SiCl}_{4}$ (all at $300^{\circ} \mathrm{K}$ ); results were plotted as percent deviation between "approximate" and "exact" transmittance vs the transmittance. In the region normally used for the determination of $Q\left(I / I_{0}\right.$ from 1.0 to 0.1$)$ the extreme deviation of $I / I_{0}$ is about $5 \%$ for $\mathrm{H}_{2}$ (the worst case). Since the average of the deviations in the desired range is less than this and since a partially compensating correction is needed for argon, the net correction would increase $Q^{*}$ by $c a 1 \%$.

It may be noted, however, that the error would become much more serious at very high attenuations; e.g. at $I / I_{0}=0.02$, errors in transmittance up to $40 \%$ may result in some cases.

\section{APPENDIX II. AVERAGE RELATIVE VELOCITY OF BEAM AND GAS MOLECULES}

The calculation of $\bar{v}_{r}$ given below is similar to that ${ }^{28}$ for a homogeneous gas except that the different velocity distribution of molecules in the beam must be taken into account.

Consider a molecule of type 2 , of speed $v_{2}$, moving in a random gas whose molecules (type 1) have a uniform speed $v_{1}$. The relative velocity $v_{y}$ of a molecule of type 2 with respect to type 1 , averaged over all directions of molecule 1 is given ${ }^{28}$ by

$$
\begin{array}{ll}
v_{r}=v_{2}+\left(v_{1}^{2} / 3 v_{2}\right) & \text { for } \quad v_{2}>v_{1} \\
v_{r}=v_{1}+\left(v_{2}{ }^{2} / 3 v_{1}\right) & \text { for } \quad v_{1}>v_{2} .
\end{array}
$$

To obtain $\bar{v}_{r}$, the average $v_{r}$ obtained from the consideration of all beam and scattering molecule velocities, one makes use of the two velocity distribution functions,

gas:

$$
d f_{1}=\left(4 / \pi^{\frac{2}{2}} \alpha_{1}^{3}\right) v_{1}^{2} \exp \left(-v_{1}^{2} / \alpha_{1}^{2}\right) d v_{1}
$$

beam: $\quad d f_{2}=\left(2 / \alpha_{2}^{4}\right) v_{2}^{3} \exp \left(-v_{2}{ }^{2} / \alpha_{2}{ }^{2}\right) d v_{2}$,

where $\alpha_{i}$ is $\left(2 k T_{i} / m_{i}\right)^{\text {t. }}$.

The average $v_{r}$ is obtained by substituting these fractions into Eq. (a) and integrating over all velocities, 
giving

$$
\begin{gathered}
\bar{v}_{r}=\left(8 / 3 \pi^{\frac{1}{2}} \alpha_{1}^{3} \alpha_{2}^{4}\right)\left[\int_{0}^{\infty} v_{3}^{2} \exp \left(-v_{2}^{2} / \alpha_{2}^{2}\right) d v_{2}\right. \\
\cdot \int_{0}^{v_{2}}\left[\left(3 v_{2}^{2}+v_{1}^{2}\right) / v_{2}\right] v_{1}^{2} \exp \left(-v_{1}^{2} / \alpha_{1}^{2}\right) d v_{1} \\
+\int_{0}^{\infty} v_{2}^{3} \exp \left(-v_{2}^{2} / \alpha_{2}^{2}\right) d v_{2} \\
\left.\cdot \int_{v_{2}}^{\infty}\left[\left(3 v_{1}^{2}+v_{2}^{2}\right) / v_{1}\right] v_{1}^{2} \exp \left(-v_{1}^{2} / \alpha_{1}^{2}\right) d v_{1}\right]
\end{gathered}
$$

The result of the integration is $\dagger$

$$
\begin{aligned}
\bar{v}_{r}=\left[3 /(\pi)^{\frac{1}{2}}\left\{\left(\alpha_{2}^{4} / 2 \beta^{2} \alpha_{1}^{3}\right)+\left(\alpha_{2}^{4} / \beta^{3} \alpha_{1}^{3}\right)\right.\right. \\
+\left(\alpha_{2}{ }^{2} / \beta^{3} \alpha_{1}\right)+\left(\alpha_{1} / 2 \beta^{2}\right) \\
\left.+\left[\left(\alpha_{2} / 2\right)+\left(\alpha_{1}^{2} / 6 \alpha_{2}\right)\right]\left[\tan ^{-1}\left(\alpha_{2} / \alpha_{1}\right)\right]\right\},
\end{aligned}
$$

where $\beta=1+\left(\alpha_{2}^{2} / \alpha_{1}{ }^{2}\right)$.

\section{APPENDIX III. THEORETICAL CORRELATION OF $Q^{*}$ FOR CERTAIN OTHER INVESTIGATIONS}

Rosin and $\mathrm{Rabi}^{2}$ measured total collision cross sections for the scattering of alkali beams in $\mathrm{H}_{2}$ and $\mathrm{D}_{2}$; they suggested that the difference in cross sections between $\mathrm{H}_{2}$ and $\mathrm{D}_{2}$ is connected with the excitation of rotational levels. From the Discussion (B), the differ-
TABLE V. Ratio of cross sections $\left(Q_{K_{2}} / Q_{K}\right)$.

\begin{tabular}{cccc}
\hline Scattering molecule & Est. $(a)$ & Est. $(b)$ & Observed $^{3}$ \\
\hline $\mathrm{H}_{2}$ & 1.33 & 1.26 & 1.26 \\
$\mathrm{D}_{2}$ & 1.35 & 1.28 & 1.36 \\
$\mathrm{He}$ & 1.34 & 1.28 & 1.21 \\
$\mathrm{~A}$ & 1.44 & 1.35 & 1.20 \\
$\mathrm{~N}_{2}$ & 1.42 & 1.35 & 1.21 \\
The uncertainty in the data is & & \\
\end{tabular}

ence in cross section of $\mathrm{H}_{2}$ and $\mathrm{D}_{2}$ should be attributable primarily to the velocity dependence of $Q$. This view is made plausible by the small difference between the $\mathrm{Li}-\mathrm{H}_{2}$ and $\mathrm{Li}-\mathrm{D}_{2}$ cross sections; here $v_{r}$ is largely determined by the comparatively high $\mathrm{Li}$ speed. The speeds of the $\mathrm{H}_{2}$ and $\mathrm{D}_{2}$ are predominant in the $v_{r}$ calculation for the other alkalis, however. The ratios of $Q$ 's for $\mathrm{H}_{2}$ and $\mathrm{D}_{2}$ from Reference 2 and as estimated from Eq. (4), respectively, are: $\mathrm{Li} 1.02,1.05 ; \mathrm{Na}$ $1.18,1.10 ; \mathrm{K} 1.30,1.12$; Rb 1.25, 1.13; Cs 1.22, 1.14 . The error in the cross sections was ${ }^{2} \pm 4 \%$ for $\mathrm{Li}, \mathrm{Na}$ and $\mathrm{K} ; \mathrm{ca} . \pm 8 \%$ for $\mathrm{Rb}$ and $\mathrm{Cs}$.

Rosenberg $^{3}$ measured the cross section of $\mathrm{K}$ and $\mathrm{K}_{2}$ in a number of gases. A reasonable explanation of his results may be obtained from Eq. (4). Only an assumption about the polarizability of $\mathrm{K}_{2}$ is needed. Two estimates of this value have been used for this calculation: (a) $\alpha_{\mathrm{K}_{2}}=2 \alpha_{\mathrm{K}}$ and (b) $\alpha_{\mathrm{K}_{2}}=2^{\frac{3}{3}} \alpha_{\mathrm{K}_{\mathrm{K}}}$. The resulting ratios of $Q$ 's are given in Table $\mathrm{V}$. 